\title{
Water Oxidation Investigated by Rapid-Scan FT-IR Spectroscopy
}

\author{
Heinz Frei \\ Molecular Biophysics Division, Lawrence Berkeley National Laboratory, \\ University of California, Berkeley, CA 94720
}




\section{Introduction}

Oxidation of water is a mandatory reaction of any photosystem for converting sunlight to the chemical energy of a fuel. The reason is that the end products of spent fuel are carbon dioxide and water, which means that a cyclic process for fuel generation and utilization requires the use of water molecules as electron source. In light of the large scale deployment required for artificial photosystems to have an impact on global fuel consumption, oxides of first row transition metals as catalysts for water oxidation have attracted special attention in recent years because of their robustness, Earth abundance, and availability in a variety of nanostructured forms. Nanostructuring provides the high surface area needed to support a sufficiently large number of catalytic sites for achieving useful product yields per geometrical area, as well as increased intrinsic rate per surface metal site. While solid oxide anodes are routinely used in commercial alkaline electrolyzers [1], it is recent breakthroughs in catalytic activity at moderate overpotential of nanosized catalysts that have opened up the use of abundant metal oxides in artificial photosystems. High surface area amorphous electrodeposits of cobalt oxide [2] and nickel oxide [3], and nanostructured crystalline $\mathrm{Co}_{3} \mathrm{O}_{4}$ or manganese oxide clusters embedded in mesoporous silica scaffolds are among early examples of substantially improved first row transition metal catalysts [4-6]. Activities expressed in terms of turnover frequency (TOF) for $\mathrm{O}_{2}$ formation per surface metal center for the extensively studied Co oxide catalysts are in the range $10^{-3}-10^{-2} \mathrm{~s}^{-1}$ under close to neutral $\mathrm{pH}$ conditions. These are determined either electrochemically or by a photosensitization method using an oxygen selective electrode or mass spectroscopic analysis of $\mathrm{O}_{2}$ gas that accumulates in the head space of the aqueous solution [2,412]. For Co oxide nanoparticles or mesoporous $\mathrm{Co}_{3} \mathrm{O}_{4}$ electrocatalysts at alkaline $\mathrm{pH}$, the more facile oxidation of hydroxide ion compared to $\mathrm{H}_{2} \mathrm{O}$ results in TOF values around $0.1 \mathrm{~s}^{-1}$ [13-18]. 
In order to guide further improvement of the efficiency of metal oxide catalysts and expand the design space for catalyst structures and morphologies, a crucial question to address is whether the observed TOF per surface Co center implies that all surface centers operate at a similar rate, or whether the value merely represents an average of widely different activities. If there are sites operating at substantially higher rates while others are much slower or inactive, it is important to identify the structural differences among these sites. Equally importantly, knowledge of the structure and kinetics of transient surface intermediates would reveal the nature of the rate limiting step. These structural and mechanistic insights will provide guidance for increasing the efficiency of the catalyst by maximizing abundance and rate of the most active sites through synthetic modification or catalyst pretreatment. In this article, recent advances in the mechanistic understanding of water oxidation by structure specific, rapid-scan FT-IR spectroscopy under reaction conditions will be presented after a brief overview of key results from electrokinetic and steady state spectroscopic studies in the past few years.

\section{Observations by steady state operando spectroscopy and electrokinetic methods}

Understanding of how water is oxidized on metal oxide surfaces has thus far mainly been based on electrokinetic and cyclic voltammetry studies combined with operando X-ray or Raman spectroscopy under steady state conditions. Among first row transition metals, Co oxide electrocatalysts have attracted the most attention in the past few years. Electrokinetic measurements have provided knowledge about fast pre-equilibria that precede the reaction with $\mathrm{H}_{2} \mathrm{O}$ on the catalyst surface to form an OO bond $\left[19^{\star}, 20\right]$, which was supported by a computational study of $\mathrm{a} \mathrm{Co}_{4} \mathrm{O}_{4}$ cubane model cluster [21]. Steady state X-ray absorption 
spectroscopy of electrocatalytic films revealed structural changes such as the formation of an oxy-hydroxide phase at applied potentials under which oxygen evolution takes place [22,23], in agreement with Raman spectroscopic measurements and theory [24,25]. This includes reversible structural change in the top surface layer of crystalline $\mathrm{Co}_{3} \mathrm{O}_{4}$ at applied potential exceeding the onset potential for driving water oxidation [26 $]$, or the accumulation of $\mathrm{Co}^{\mathrm{IV}}$ centers under these conditions $[27,28]$. Optical spectroelectrochemical monitoring of water oxidation over hematite photocatalyst $\left(\alpha-\mathrm{Fe}_{2} \mathrm{O}_{3}\right)$ under steady state conditions allowed the detection of a species absorbing at $572 \mathrm{~nm}$ tentatively assigned to an oxo $\mathrm{Fe}^{\mathrm{IV}}$ site based on spectral similarity with a molecular complex featuring a $\mathrm{Fe}^{\mathrm{IV}}=\mathrm{O}$ group $\left[29^{\bullet}\right]$.

Identification of the molecular structure of catalytic surface intermediates and determination of their kinetic relevancy eludes electrochemical and steady state operando methods, awaiting studies by a structure specific spectroscopy with sufficient temporal resolution to reveal the kinetics of elementary steps of the catalytic cycle under reaction conditions. This has recently been enabled by time-resolved FT-IR spectroscopy of aqueous suspensions of $\mathrm{Co}_{3} \mathrm{O}_{4}$ crystalline nanoparticles in the attenuated total reflection configuration (ATR), starting with the rapid-scan method.

\section{Rapid-scan FT-IR spectroscopy under reaction conditions}

Transient spectroscopic monitoring of catalysis requires pulsed initiation of the reaction while probing the sample continuously. For the rapid-scan FT-IR method, one or a few spectra are measured during the light pulse, and a series of spectra after termination of the pulse (schematically presented in Figure 1A). It is the kinetic behavior during the dark period that 
reveals the reactivity of a given intermediate. A widely used visible light sensitization system for driving water oxidation catalysts consisting of $\left[\mathrm{Ru}(\mathrm{bpy})_{3}\right]^{2+}$ complex and $\mathrm{S}_{2} \mathrm{O}_{8}{ }^{2-}$ electron acceptor allows the generation of oxidized $\left[\mathrm{Ru}(\mathrm{bpy})_{3}\right]^{3+}$ species with a laser light pulse of any desired duration. Upon collision with a $\mathrm{Co}_{3} \mathrm{O}_{4}$ nanoparticle in close to neutral aqueous solution, a hole is transferred from $\left[\mathrm{Ru}(\mathrm{bpy})_{3}\right]^{3+}$ to the catalyst at well-defined energy $(+1.26 \mathrm{~V})$, as illustrated in Figure 1B. Sequential transfer of four holes to a particle converts two $\mathrm{H}_{2} \mathrm{O}$ molecules to $\mathrm{O}_{2}$ and four $\mathrm{H}^{+}$.

When illuminating an aqueous suspension of surfactant-free $\mathrm{Co}_{3} \mathrm{O}_{4}$ nanocrystals $(4 \mathrm{~nm}, \mathrm{pH} 7.5)$ containing $\left[\mathrm{Ru}(\mathrm{bpy})_{3}\right]^{2+}$ and persulfate electron acceptor with a $476 \mathrm{~nm}$ laser pulse of $300 \mathrm{~ms}$ duration (Figure 1C), two surface intermediates with distinct kinetic behavior were detected [ $\left.8^{\bullet}\right]$. One is a superoxide species absorbing at $1013 \mathrm{~cm}^{-1}$ which exhibits an O-O stretch mode characteristic for interaction with two surface metal centers, shown in Figure 2Aa. Isotopically shifted bands at 995 and $966 \mathrm{~cm}^{-1}$ observed when conducting an experiment using unlabeled $\mathrm{Co}_{3}{ }^{16} \mathrm{O}_{4}$ nanoparticles suspended in pure $\mathrm{H}_{2}{ }^{18} \mathrm{O}$ show a $1: 1$ ratio of superoxide ${ }^{18} \mathrm{O}^{16} \mathrm{O}\left(995 \mathrm{~cm}^{-1}\right)$ and fully labeled ${ }^{18} \mathrm{O}^{18} \mathrm{O}\left(966 \mathrm{~cm}^{-1}\right)$ after a single $300 \mathrm{~ms}$ pulse (Figure $2 \mathrm{Ab}$ and Figure $\left.3 \mathrm{~A}\right)$. The large, $47 \mathrm{~cm}^{-1}$ isotope shift of the $966 \mathrm{~cm}^{-1}$ band confirms the assignment to an O-O bond mode, while a modest $\mathrm{D}$ isotope shift of $38 \mathrm{~cm}^{-1}$ in $\mathrm{D}_{2} \mathrm{O}\left(975 \mathrm{~cm}^{-1}\right.$, Figure $\left.2 \mathrm{Ac}\right)$ indicates hydrogen bonding interaction of the superoxide moiety, most likely with an adjacent Co hydroxyl group. Most of the rise of the superoxide intermediate occurs during the $300 \mathrm{~ms}$ illumination pulse, with continued growth after termination of the pulse until all hole-injecting $\left[\mathrm{Ru}(\mathrm{bpy})_{3}\right]^{3+}$ species are consumed, as can be seen in Figure 2D (black trace). The concentration of the superoxide so produced does not change appreciably in the subsequent dark period even on the several second 
timescale, which is to be expected given the known stability of superoxide species on metal surfaces; this 3-electron oxidation intermediate requires the delivery of one additional hole by continued illumination for liberating $\mathrm{O}_{2}$ and restarting the catalytic cycle.

Electrochemical detection of $\mathrm{O}_{2}$ by Clark electrode measurement following a $300 \mathrm{~ms}$ light pulse indicates that a substantial fraction of the catalytic sites complete the cycle in this short illumination period. $\left[8^{\bullet}\right]$ Mass spectrometric analysis of the isotopic composition of the oxygen gas accumulating in the head space in experiments with unlabeled $\mathrm{Co}_{3}{ }^{16} \mathrm{O}_{4}$ in pure $\mathrm{H}_{2}{ }^{18} \mathrm{O}$ on the several minute time scale gave a ratio of 8:1 for fully labeled ${ }^{18} \mathrm{O}_{2}$ versus partially labeled ${ }^{18} \mathrm{O}^{16} \mathrm{O}$ (no unlabeled ${ }^{16} \mathrm{O}_{2}$ was detected, Figure 2C). The agreement between the isotopic composition of the $\mathrm{O}_{2}$ product and the superoxide intermediate after 5 light pulses (inset of Figure $2 \mathrm{Ab}$ ) constitutes compelling evidence that the surface superoxide is a kinetically relevant intermediate of the catalytic cycle for water oxidation by $\mathrm{Co}_{3} \mathrm{O}_{4}$.

The second transient infrared band observed at $840 \mathrm{~cm}^{-1}$ does not exhibit any isotopic shift when conducting the photocatalysis in $\mathrm{H}_{2}{ }^{18} \mathrm{O}$ or $\mathrm{D}_{2} \mathrm{O}$ as shown in Figure $2 \mathrm{~B}$, which points strongly to a $\mathrm{Co}^{\mathrm{IV}}=\mathrm{O}$ oxo intermediate $\left[8^{\bullet}\right]$ (resonant with oxyl $\mathrm{Co}^{\mathrm{III}}-\mathrm{O}$, which may more accurately reflect the electronic structure of the site). In contrast to superoxide, the oxo species decreases spontaneously in the dark with a rate constant of $1 \mathrm{~s}^{-1}$ (Figure 2D, red trace), which is attributed to $\mathrm{O}-\mathrm{O}$ chemical bond formation with a $\mathrm{H}_{2} \mathrm{O}$ molecule. Because the decay kinetics is much slower than the rise of the superoxide species, the $840 \mathrm{~cm}^{-1} \mathrm{Co}^{\mathrm{IV}}=\mathrm{O}$ intermediate cannot be the precursor of the observed superoxide at $1013 \mathrm{~cm}^{-1}$. The $840 \mathrm{~cm}^{-1}$ oxo group therefore belongs to a much less active site that closes the $\mathrm{O}_{2}$ producing catalytic cycle on an at least a 150 times 
slower time scale $\left[8^{\bullet}\right]$. The $\mathrm{Co}^{\mathrm{IV}}=\mathrm{O}$ surface species has not been detected before by vibrational spectroscopy, but observed ex situ by low temperature EPR following electrochemical water oxidation using Co oxide electrodeposits [30].

\section{Mechanism of water oxidation catalysis}

Our proposed motif for the fast catalytic site are adjacent oxo-bridged octahedral $\mathrm{Co}^{\mathrm{III}}-\mathrm{OH}$ groups, i.e. $\mathrm{Co}(\mathrm{OH})-\mathrm{O}-\mathrm{CoOH}$ based on insights from cyclic voltammetry of Co oxide electrocatalysts and Pourbaix analyses of layered Co double hydroxides mentioned above, which feature this motif $\left[19^{\star}\right]$. Therefore, the most plausible mechanism of the fast catalytic cycle on $\mathrm{Co}_{3} \mathrm{O}_{4}$ surfaces starts with a $\mathrm{Co}{ }^{\mathrm{III}}(\mathrm{OH})-\mathrm{O}-\mathrm{Co}^{\mathrm{III}} \mathrm{OH}$ moiety that is converted by two sequentially arriving holes to $\mathrm{Co}^{\mathrm{IV}}(=\mathrm{O})-\mathrm{O}-\mathrm{Co}^{\mathrm{IV}}=\mathrm{O}$ intermediate accompanied by deprotonation, as shown in Figure 3B. This site is expected to undergo facile $\mathrm{O}-\mathrm{O}$ bond formation by spontaneous nucleophilic attack (in the dark) of $\mathrm{H}_{2} \mathrm{O}$ on one of the $\mathrm{Co}^{\mathrm{IV}}=\mathrm{O}$ groups to yield a $\mathrm{Co}^{\mathrm{III}} \mathrm{OOH}$ hydroperoxide surface species. Subsequent arrival of another hole leads to the formation of the observed superoxide intermediate absorbing at $1013 \mathrm{~cm}^{-1}$. Elimination of $\mathrm{O}_{2}$ upon delivery of a further hole opens a coordination site for a $\mathrm{H}_{2} \mathrm{O}$ molecule, thereby regenerating the $\mathrm{Co}^{\mathrm{III}}-\mathrm{OH}$ center. Because $\mathrm{O}_{2}$ product is already observed for a $300 \mathrm{~ms}$ light pulse, this fast site has a TOF of approx. $3 \mathrm{~s}^{-1}$, exceeding the average value of $0.02 \mathrm{~s}^{-1}$ derived from steady state measurements by over 2 orders of magnitude. Hence, the rapid-scan FT-IR study reveals that even for single crystal $\mathrm{Co}_{3} \mathrm{O}_{4}$ nanoparticles, surface sites with widely different catalytic activity exist. In recent DFT computational work on water oxidation on $\mathrm{Co}_{3} \mathrm{O}_{4}$ that include for the first time calculation of activation barriers, Plaisance and van Santen found $\mathrm{Co}^{\mathrm{IV}}(=\mathrm{O})-\mathrm{O}-\mathrm{Co}^{\mathrm{IV}}=\mathrm{O}$ moieties to be sites with the highest TOF at low and moderate overpotential depending on the $\mathrm{Co}_{3} \mathrm{O}_{4}$ crystal 
facet. $\left[31,32^{\star}\right]$ The $\mathrm{Co}^{\mathrm{IV}}(=\mathrm{O})-\mathrm{O}-\mathrm{Co}^{\mathrm{IV}}=\mathrm{O}$ features nucleophilic attack by a water molecule as proposed in our mechanism, although preferentially on the bridging $\mathrm{O}$ according to the calculation rather than a terminal oxo proposed in Figure 3B.

For $\mathrm{Co}^{\mathrm{III}}-\mathrm{OH}$ sites on the $\mathrm{Co}_{3} \mathrm{O}_{4}$ surface that lack an adjacent $\mathrm{Co}{ }^{\mathrm{III}}-\mathrm{OH}$ group illustrated by the $\mathrm{Co}^{\mathrm{III}} \mathrm{OH}$ site in the left corner of the $\mathrm{Co}_{3} \mathrm{O}_{4}(111)$ facet depicted in the cartoon of Figure $3 \mathrm{C}$, the $\mathrm{Co}^{\mathrm{IV}}=\mathrm{O}$ intermediate generated upon hole transfer is unable to couple to another $\mathrm{Co}^{\mathrm{IV}}=\mathrm{O}$. Nucleophilic attack of an $\mathrm{H}_{2} \mathrm{O}$ molecule on such isolated oxo $\mathrm{Co}^{\mathrm{IV}}$ groups faces barriers not present for the $\mathrm{Co}^{\mathrm{IV}}(=\mathrm{O})-\mathrm{O}-\mathrm{Co}^{\mathrm{IV}}=\mathrm{O}$ sites. Specifically, reduction of the Co center proceeds to $\mathrm{Co}^{\mathrm{II}}$ which likely requires spin flip and involves deprotonation of $\mathrm{H}_{2} \mathrm{O}$, the latter accompanied by an activation barrier not present for reaction of $\mathrm{H}_{2} \mathrm{O}$ at the $\mathrm{Co}^{\mathrm{IV}}(=\mathrm{O})-\mathrm{O}-\mathrm{Co}^{\mathrm{IV}}=\mathrm{O}$ site. Furthermore, the site lacks the extra oxidation power of an adjacent, electronically coupled $\mathrm{Co}^{\text {IV }}$ center. Hence, the O-O bond forming step of an isolated Co site by nucleophilic attack of $\mathrm{H}_{2} \mathrm{O}$ is expected to be a slow spontaneous reaction. We attribute the $840 \mathrm{~cm}^{-1}$ species and its long decay of $1 \mathrm{~s}^{-1}$ to such Co surface centers that lack the ability to couple via $\mathrm{O}$ bridge to a $\mathrm{Co}^{\mathrm{IV}}$ site during the catalytic cycle (Figures 3B, bottom). In the recent DFT study, isolated Co surface centers were calculated to exhibit high TOF under large overpotential involving highly oxidized $\mathrm{Co}^{\mathrm{V}}$ surface centers $\left[31,32^{\star}\right]$.

\footnotetext{
Recent reports from other labs using different experimental techniques provide interesting insights which corroborate the findings of the rapid-scan FT-IR work. In a study of TOF of Co oxide electrocatalysts by a fast, spatially resolved surface interrogation SEM technique, Ahn and Bard found a TOF of $\mathrm{Co}^{\mathrm{IV}}$ oxo sites of $3.2 \mathrm{~s}^{-1}$, in good agreement with the value for the fast
} 
catalytic site found by the rapid-scan FT-IR method $\left[33^{\bullet}, 34\right]$. When monitoring electrochemically driven water oxidation over $\mathrm{Ni}$ oxy hydroxide by steady state surface enhanced Raman spectroscopy, Koper and coworker detected the formation of superoxide surface intermediate absorbing at $1000 \mathrm{~cm}^{-1}$ [35]. Hence, superoxide as catalytic surface intermediate seems not be confined to water oxidation on $\mathrm{Co}_{3} \mathrm{O}_{4}$ surfaces, suggesting that the reaction path identified by rapid-scan FT-IR measurements might be of more general significance for water oxidation on metal oxide surfaces.

For observing the yet to be detected one- and two-electron oxidation intermediates and associated kinetics (Figure 3B, top), especially the O-O bond forming step of the fast catalytic site of water oxidation on $\mathrm{Co}_{3} \mathrm{O}_{4}$ surfaces, recording of FT-IR spectra at higher time resolution is required. Rapid-scan FT-IR spectroscopy at acceptable spectral resolution $\left(4 \mathrm{~cm}^{-1}\right)$ can be conducted at $20 \mathrm{~ms}$ temporal resolution, and step-scan FT-IR spectroscopy affords resolution as short as $20 \mathrm{~ns}$. These methods have been applied to various heterogeneous catalytic systems and are well established [36]. Hence, the challenge of FT-IR monitoring at high time resolution is not the spectroscopic technique per se, but establishing adequate sensitivity for detecting short lived infrared species. A recent example for such a situation is the observation of surface IrOOH (hydroperoxide) intermediate of water oxidation at Ir oxide nanoparticles by its OO stretch absorption at $830 \mathrm{~cm}^{-1}$ by the rapid-scan FT-IR method [37]. In order to detect the infrared mode in ATR measurement configuration, illumination with visible light photosensitization pulses of 1 s duration was required. While allowing us to observe the surface intermediate and identify its structure by ${ }^{18} \mathrm{O}$ and $\mathrm{D}$ isotopic labeling, the pulse length was too long for temporally resolving the fast decay of the species, reflecting the well known high efficiency of Ir oxide catalysts 
[38,39]. Only light-on/light-off spectra could be recorded. Therefore, future efforts need to focus on spectral sensitivity improvement of the ATR FT-IR method at the solid-aqueous interface.

Furthermore, time-resolved X-ray spectroscopic studies would be extremely useful for elucidating the electronic structure and dynamics of the surface metal centers that accompany the formation and reaction of molecular intermediates detected by dynamic FT-IR spectroscopy. In fact, in the case of water oxidation at Ir oxide nanoparticles, recent high pressure XPS measurements under electrocatalytic conditions revealed the formation of $\operatorname{Ir}^{\mathrm{V}}$ suggesting that the surface intermediate observed in the rapid-scan FT-IR study is Ir ${ }^{\mathrm{III}} \mathrm{OOH}$, formed by reaction of $\mathrm{H}_{2} \mathrm{O}$ at $\mathrm{Ir}^{\mathrm{V}}=\mathrm{O}$ sites $\left[40^{\circ}\right]$. Combined transient FT-IR and time-resolved X-ray absorption measurements should reveal the molecular structure and kinetics of surface intermediates and the change of the electronic state of the surface metal centers along the catalytic path.

\section{Outlook}

The direct observation of intermediates of water oxidation and their kinetic behavior at the aqueous-solid interface of heterogeneous catalysts by time-resolved rapid-scan FT-IR opens up insight into elementary bond making/breaking steps at the molecular level. The temporal resolution of this structure specific spectroscopy allows us to evaluate of the role of surface intermediates in the catalytic cycle under reaction conditions and, together with the isotopic signature of sequential intermediates and final product, to determine the catalytic relevancy of observed species. Knowledge of the molecular structure of transient surface intermediates and identification of kinetic bottlenecks provide powerful guidance for catalyst improvements. If combined with simultaneous time resolved X-ray monitoring of accompanying electronic 
structure changes of surface metal centers, catalytic mechanisms can be unraveled at unprecedented level of detail.

\section{Acknowledgement}

This work was supported by the Director, Office of Science, Office of Basic Energy Sciences,

Division of Chemical, Geological and Biosciences of the U.S. Department of Energy under

Contract No. DE-AC02-05CH11231. 
References and recommended reading

Papers of particular interest, published within the period of review, have been highlights as:

- of special interest

* of outstanding interest

[1] Trasatti S: In Electrochemistry of Novel Materials. Edited by Lipkowksi J, Ross PN. VCH Publishers; 1994

[2] Kanan MW, Nocera DG: In Situ formation of an oxygen-evolving catalyst in neutral water containing phosphate and $\mathrm{Co}^{2+}$. Science 2008, 321:1072-1075.

[3] Dinca M, Surendranath Y, Nocera DG: Nickel-borate oxygen-evolving catalyst that functions under benign conditions. Proc Natl Acad Sci USA 2010, 107:10337-10341.

[4] Jiao F, Frei H: Nanostructured cobalt oxide clusters in mesoporous silica as efficient oxygen-evolving catalyst. Angew Chem Int Ed 2009, 48:1841-1844.

[5] Jiao F., Frei H: Nanostructured manganese oxide clusters supported on mesoporous silica as efficient oxygen-evolving catalysts. Chem Coтmun 2010, 46:2920-2922.

[6] Jiao F, Frei H: Nanostructured cobalt and manganese oxide clusters as efficient water oxidation catalysts. Energy Environ Sci 2010, 3:1018-1027.

[7] Zhang M, Frei H: Towards a molecular level understanding of the multi-electron catalysis of water oxidation on metal oxide surfaces. Catal Lett 2015, 145:420-435.

[8] Zhang M, de Respinis M, Frei H: Time-resolved observations of water oxidation intermediates on a cobalt oxide nanoparticle catalyst. Nature Chem 2014, 6:362-367.

- Detection and identification of transient surface intermediates by a structure specific vibrational spectroscopy (FT-IR) under reaction conditions, which reveals the presence of different catalytic sites and the turnover frequency for each. 
[9] Grzelczak M, Zhang J, Pfrommer J, Hartmann J, Driess M, Antonietti M, Wang X: Electro- and photochemical water oxidation on ligand-free $\mathrm{Co}_{3} \mathrm{O}_{4}$ nanoparticles with tunable sizes. ACS Catal 2013, 3:383-388.

[10] Yusuf S, Jiao F: Effect of the support on the photocatalytic water oxidation activity of cobalt oxide nanoclusters. ACS Catal 2012, 2:2753-2760.

[11] Boppana VBR, Jiao F: Nanostructured $\mathrm{MnO}_{2}$ : An efficient and robust water oxidation catalyst. Chem Commun 2011, 47:8973-8975.

[12] Koroidov S, Anderlund MF, Styring S, Thapper A, Messinger J: First turnover analysis of water oxidation catalyzed by Co oxide nanoparticles. Energy Environ Sci 2015, 8:2492-2503.

[13] Esswein AJ, McMurdo MJ, Ross PN, Bell AT, Tilley TD: Size-dependent activity of $\mathrm{Co}_{3} \mathrm{O}_{4}$ nanoparticle anodes for alkaline water electrolysis. J Phys Chem C 2009, 113:15068-15072.

[14] Blakemore JD, Gray HB, Winkler JR, Mueller AM: $\mathbf{C o}_{3} \mathbf{O}_{4}$ nanoparticle water oxidation catalysts made by pulsed-laser ablation in liquids. ACS Catal 2013, 3:24972500.

[15] Hutchings GS, Zhang Y, Li J, Yonemoto BT, Zhou X, Zhu K, Jiao F: In situ formation of cobalt oxide nanocubanes as efficient oxygen evolution catalysts. $J$ Am Chem Soc 2015, 137:4223-4229.

[16] Menezes PW, Indra A, Gonzalez-Flores D, Saharaie NR, Zaharieva I, Schwarze M, Strasser P, Dau H, Driess M: High performance oxygen redox catalysis with multifunctional cobalt oxide nanochains: Morphology-dependent activity. ACS Catal 2015, 5:2017-2027. 
[17] Tuysuz H, Hwang YJ, Khan SB, Asiri AM, Yang P: Mesoporous $\mathrm{Co}_{3} \mathbf{O}_{4}$ as an electrocatalyst for water oxidation. Nano Res 2013, 6:47-54.

[18] Sa YJ, Kwon K, Cheon JY, Kleitz F, Joo SH: Ordered mesoporous $\mathrm{Co}_{3} \mathrm{O}_{4}$ spinels as stable, bifunctional, noble metal-free oxygen electrocatalysts. J Mater Chem A 2013, 1:9992-10001.

[19] Gerken JB, McAlpin JG, Chen JYC, Rigsby, ML, Casey WH, Britt RD, Stahl SS: Electrochemical water oxidation with cobalt-based electrocatalysts from pH 0-14: The thermodynamic basis for catalyst structure, stability, and activity. J Am Chem Soc 2011, 133:14431-14442.

* This paper is an excellent description and explanation of mechanistic insights of heterogeneous water oxidation catalysis that can be gained from electrochemical studies.

[20] Surendranath Y, Kanan MW, Nocera DG: Mechanistic studies of the oxygen evolution reaction by a cobalt-phosphate catalyst at neutral pH. J Am Chem Soc 2010, 132:16501-16509.

[21] Wang LP, Van Voorhis T: Direct-coupling $\mathbf{O}_{2}$ bond forming a pathway in cobalt oxide water oxidation catalysts. J Phys Chem Lett 2011, 2:2200-2204.

[22] Subbaraman R, Tripkovic D, Chang KC, Strmenik D, Paulias AP, Hirunsit P, Chan M, Greeley J, Stamenkovic D, Markovic NM: Trends in activity for the water electrolyser reactions on 3d M(Ni, Co, Fe, Mn) hydr(oxy)oxide catalysts. Nature Mater 2012, 11:550-557.

[23] Wang HY, Hung SF, Chen HY, Chan TS, Chen HM, Liu B: In operando identification of geometrical site dependent water oxidation activity of spinel $\mathrm{Co}_{3} \mathrm{O}_{4} . J \mathrm{Am}$ Chem Soc 2016, 138:36-39. 
[24] Yeo BS, Bell AT: Enhanced activity of gold-supported cobalt oxide for the electrochemical evolution of oxygen. J Am Chem Soc 2011, 133:5587-5593.

[25] Bajdich M, Garcia-Mota M, Vojvodic A, Norskov JK, Bell AT: Theoretical investigation of the activity of cobalt oxides for the electrochemical oxidation of water. J Am Chem Soc 2013, 135:13521-13530.

[26] Bergmann A, Martinez-Moreno E, Teschner D, Chernev P, Gliech M, Ferreira de Araujo, J, Reier T, Dau H, Strasser P: Reversible amorphization and the catalytic active state of crystalline $\mathrm{Co}_{3} \mathrm{O}_{4}$ during oxygen evolution. Nature Commun 2015, 6:8625.

*xcellent report on how X-ray spectroscopy is able to reveal detailed reversible structural changes of the top surface layers of a metal oxide catalyst under electrocatalytic conditions.

[27] Kanan MW, Yano J, Surendranath Y, Dinca M, Yachandra VK, Nocera DG: Structure and valency of a cobalt-phosphate water oxidation catalyst determined by in situ Xray spectroscopy. J Am Chem Soc 2010, 132:13692-13701.

[28] Friebel D, Bajdich M, Yeo BS, Louie MW, Miller DJ, Sanchez-Casalongue H, Mbuga F, Weng TC, Nordlund D, Sokaras D, Alonso-Mori R, Bell AT, Nilsson A: On the chemical state of Co oxide electrocatalysts during alkaline water splitting. Phys Chem Chem Phys 2013, 15:17460-17467.

[29] Klahr B, Hamann T: Water oxidation on hematite photoelectrodes: Insight into the nature of surface states through in-situ spectroelectrochemistry. J Phys Chem C 2014, 118:10393-10399. 
[31] Plaisance CP, van Santen RA: Structure sensitivity of the oxygen evolution reaction catalyzed by cobalt(II,III) oxide. J Am Chem Soc 2015, 137:14660-14672.

[32] Plaisance CP, Reuter K, van Santen RA: Quantum Chemistry of the oxygen evolution reaction on cobalt(II,III) oxide - implications for designing the optimal catalyst. Faraday Discuss 2016. DOI: 10.1039/C5FD00213C

* The paper reports theoretical treatment (DFT) of water oxidation catalysis on metal oxide surfaces that includes for the first time the calculation of activation barriers for individual steps, which proves essential for predicting rate limiting steps on various crystallographic facets.

[33] Ahn HS, Bard AJ: Surface interrogation of CoPi water oxidation catalyst by scanning electrochemical microscopy. J Am Chem Soc 2015, 137:612-615.

- The paper introduces a novel microscopic method for determining turnover frequencies of individual catalytic sites on solid catalyst surfaces.

[34] Ahn HS, Bard AJ: Switching transient generation in surface interrogation scanning electron microscopy and time-of-flight techniques. Anal Chem 2015, 87:12276-12280. 
[35] Diaz-Morales O, Ferrus-Suspedra D, Koper MTM: The importance of nickel oxyhydroxide deprotonation on its activity towards electrochemical water oxidation. Chem Sci 2016, DOI: 10.1039/c5sc04486c

[36] Yeom YH, Frei H: Time-resolved step-scan and rapid-scan Fourier-transform infrared spectroscopy. In In-Situ Spectroscopy of Catalysts. Edited by Weckhysen BM. American Scientific Publishers; 2004:32-46.

[37] Sivansankar N, Weare WW, Frei H: Direct observation of a hydroperoxide surface intermediate upon visible light driven water oxidation at an Ir oxide nanocluster catalyst by rapid-scan FT-IR spectroscopy. J Am Chem Soc 2011, 133:12976-12979.

[38] Nakagawa T, Bjorge NS, Murray RW: Electrogenerated IrO $_{\mathbf{x}}$ nanoparticles as dissolved redox catalysts for water oxidation. $J$ Am Chem Soc 2009, 131:15578-15579.

[39] Kuwabara T, Tomita E, Sakita S, Hasegawa D, Sone K, Yagi K: Characterization and analysis of self-assembly of a highly active colloidal catalyst for water oxidation onto transparent conducting oxide substrates. J Phys Chem C 2008, 112:3774-3779.

[40] Sanchez-Casalongue HG, Ng ML, Kaya S, Friebel D, Ogasawara H, Nilsson A: In situ observation of surface species on iridium oxide nanoparticles during the oxygen evolution reaction. Angew Chem Int Ed 2014, 53:7169-7172.

- In-situ ambient pressure XPS measurements allow the determination of the oxidation state of surface metal centers of a metal oxide catalyst under steady state water oxidation conditions. 
A)

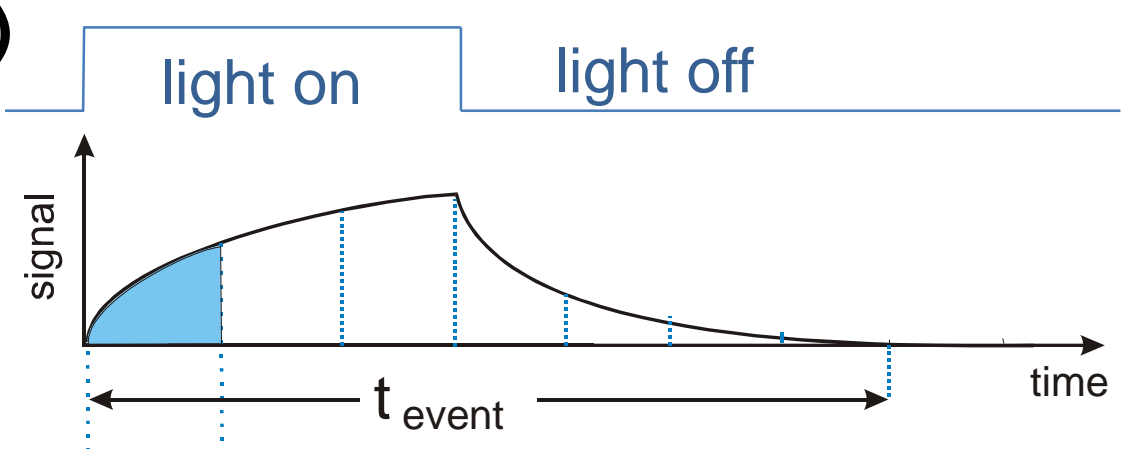

C)

\section{aqueous suspension}

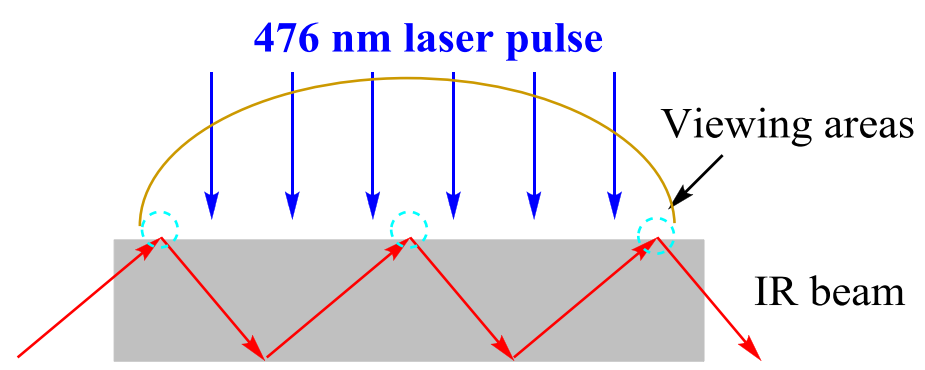

\section{Attenuated total reflection diamond plate}

B)

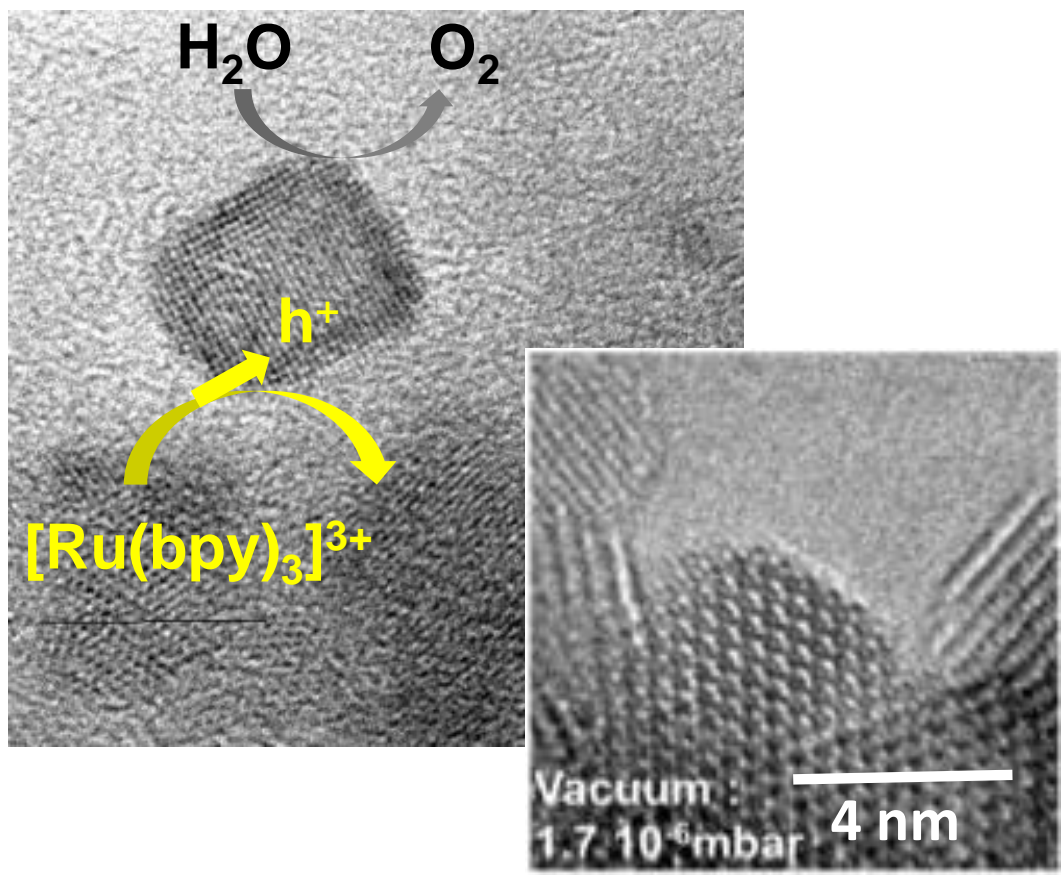

$$
\begin{aligned}
{\left[\mathrm{Ru}(\mathrm{bpy})_{3}\right]^{2+}+\mathrm{S}_{2} \mathrm{O}_{8}{ }^{2-} \stackrel{\mathrm{hv}}{\rightarrow}\left[\mathrm{Ru}(\mathrm{bpy})_{3}\right]^{3+}+\mathrm{SO}_{4}{ }^{2-}+\mathrm{SO}_{4}{ }^{-} } \\
{\left[\mathrm{Ru}(\mathrm{bpy})_{3}\right]^{2+}+\mathrm{SO}_{4}^{-} \cdot \rightarrow\left[\mathrm{Ru}(\mathrm{bpy})_{3}\right]^{3+}+\mathrm{SO}_{4}{ }^{2-} }
\end{aligned}
$$

Figure 1: A) Concept of temporally resolved FT-IR spectroscopy of photocatalysis. B) Atomic resolution TEM image of $5 \mathrm{~nm}$ $\mathrm{Co}_{3} \mathrm{O}_{4}$ crystallite. C) Sample configuration for rapid-scan ATR FT-IR spectroscopy. A visible laser pulse (476 nm, $\left.300 \mathrm{~ms}\right)$ excites the $\mathrm{Ru}(\mathrm{bpy})_{3}$ sensitizer in an aqueous suspension of $\mathrm{Co}_{3} \mathrm{O}_{4}$ nanocrystals placed on a diamond ATR element with 3 infrared reflections. B) and C) are from Ref. 7, with permission. 

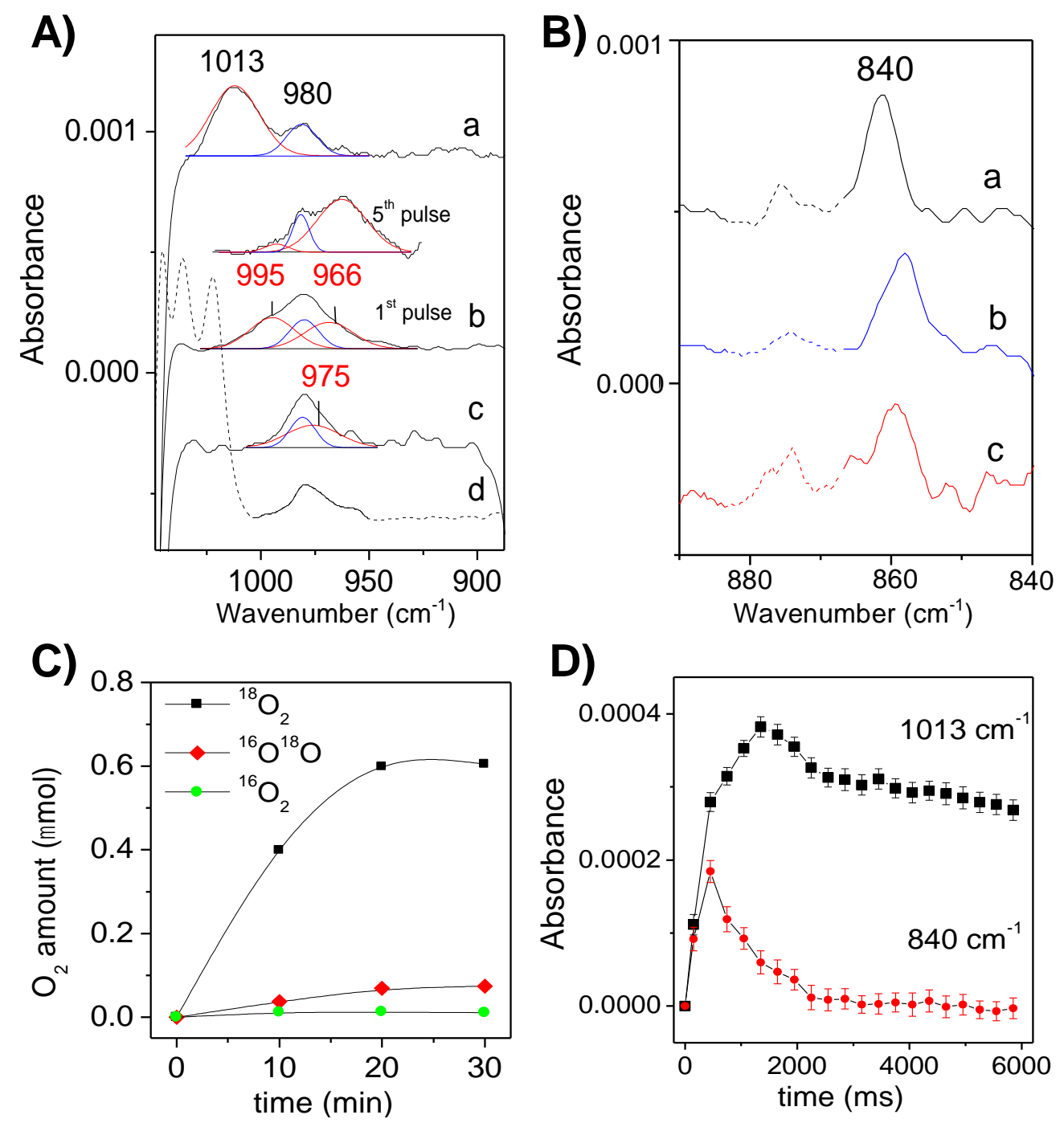

Figure 2: Time resolved FT-IR monitoring of water oxidation catalysis at $\mathrm{Co}_{3} \mathrm{O}_{4}$ nanoparticles. A) FT-IR of superoxide intermediate $\mathrm{Co}^{\mathrm{III}}-(\mathrm{OO})-\mathrm{Co}^{\mathrm{III}}$ at $5850 \mathrm{~nm}$ after onset of a $300 \mathrm{~ms}$ photolysis laser pulse a) in $\left.\mathrm{H}_{2}{ }^{16} \mathrm{O}, \mathrm{b}\right) \mathrm{H}_{2}{ }^{18} \mathrm{O}$ (inset: spectral trace after 5 laser pulses), c) $\mathrm{D}_{2} \mathrm{O}$, d) control experiment, no $\mathrm{Co}_{3} \mathrm{O}_{4}$ present. Red: superoxide bands, blue $\mathrm{SO}_{4}{ }^{2-}$ growth (reduced acceptor). $\mathrm{B}$ ) $\mathrm{Co}^{\mathrm{IV}}=\mathrm{O}$ intermediate in a) $\mathrm{H}_{2}{ }^{16} \mathrm{O}$, b) $\mathrm{H}_{2}{ }^{18} \mathrm{O}$, c) $\mathrm{D}_{2} \mathrm{O}$. C) Isotopic composition of $\mathrm{O}_{2}$ gas accumulated in headspace measured by mass spectroscopy. D) Temporal behavior of superoxide (black) and $\mathrm{Co}^{\mathrm{IV}}=\mathrm{O}$ intermediate (red). From refs. 7 and $8^{\bullet}$, with permission. 
A)

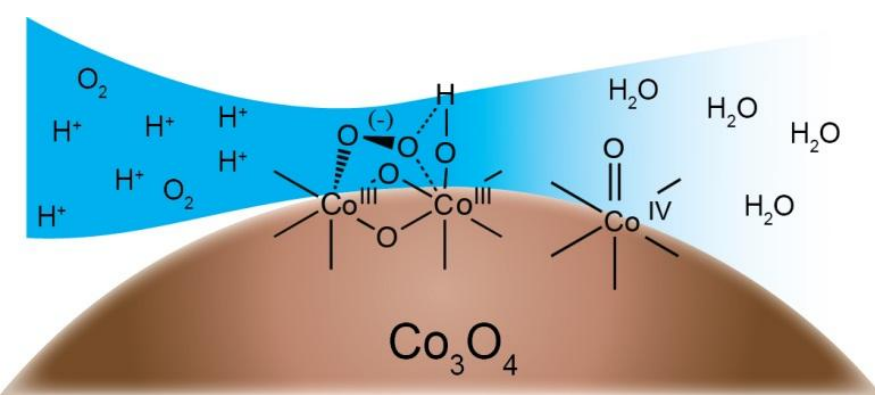

C)

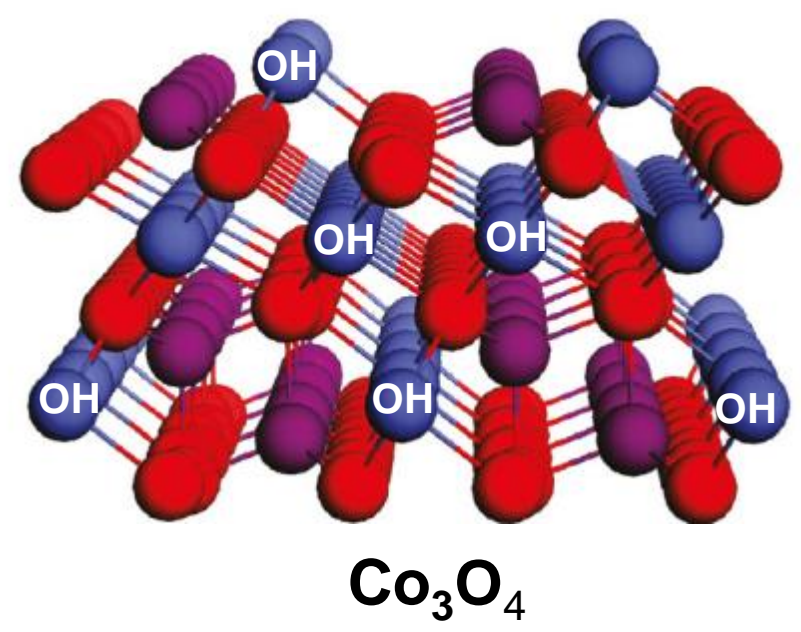

B)

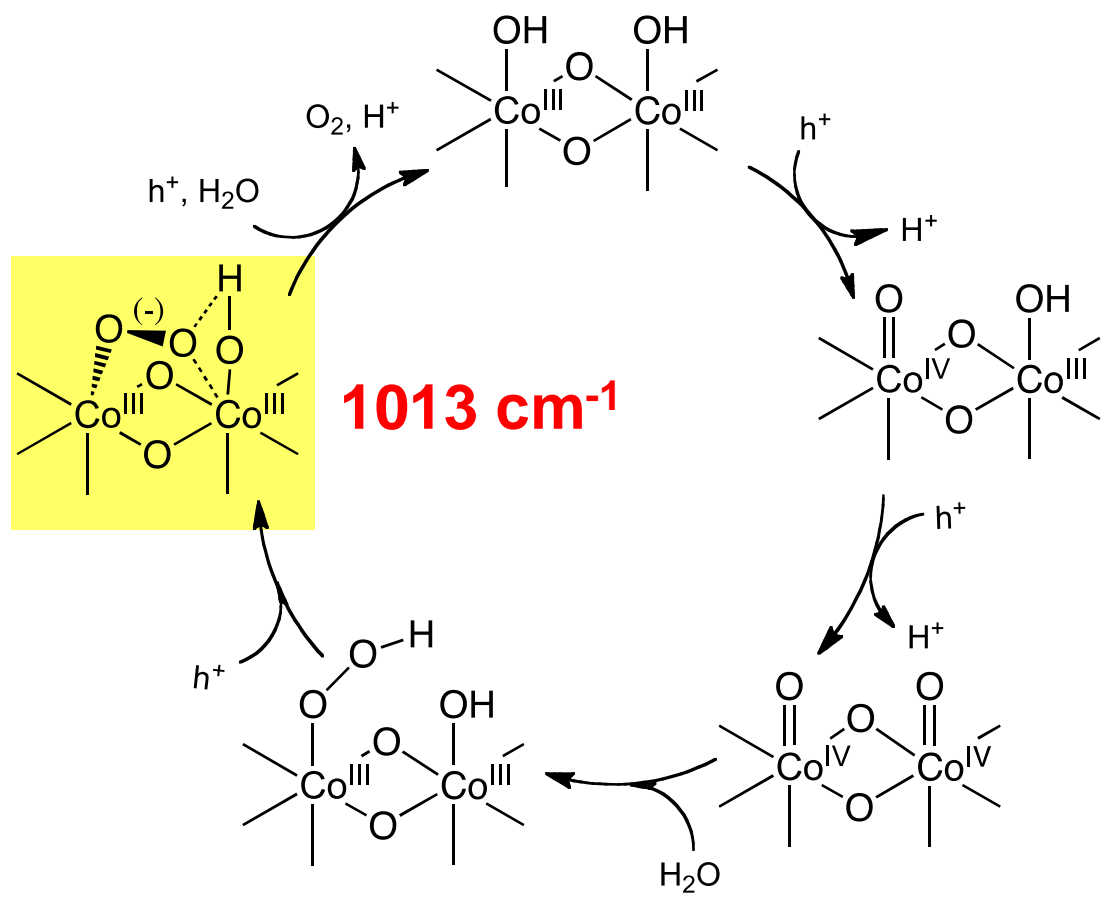

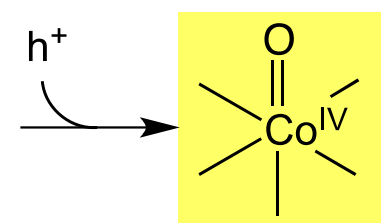

$840 \mathrm{~cm}^{-1}$

Figure 3: Proposed reaction mechanism of water oxidation on $\mathrm{Co}_{3} \mathrm{O}_{4}$ surface. A) Cartoon showing structure of observed intermediates. B) Mechanism of fast site (top) and slow site (bottom). From Ref. $\mathbf{8}^{\bullet}$, with permission. C) Partially OH terminated $\mathrm{Co}_{3} \mathrm{O}_{4}(111)$ surface illustrates octahedral $\mathrm{Co}^{\mathrm{III}}-\mathrm{OH}$ surface centers with, and without, adjacent $\mathrm{Co}^{\mathrm{III}}-\mathrm{OH}$ group. $\mathrm{Co}^{\mathrm{III}}$, blue; $\mathrm{Co}^{\mathrm{II}}$, purple; $\mathrm{O}$, red. 